\title{
Leadership styles and approaches in \\ GeoSciences
}

\section{Katriona Edlmann}

In common with many of my academic colleagues, I entered the University to excel in my research and teaching rather than to become a leader; this article explores how senior academics often "learn as they go".

Excellent leadership within UK universities is more important than ever, as increasing fees, internationalisation and reducing research budgets lead to an ever more competitive research market. Current research indicates that successful leadership within an academic environment should be non-coercive, based on teamwork and relationships (Moss \& Jensrud, 1995; McCafffery, 2004). Within the School of GeoSciences at the University of Edinburgh, the 2015 Athena SWAN statistics reveal that the school has $39 \%$ female staff at grade Uog and $15 \%$ female staff at grade U10, which is similar to the overall University female academic staff ratio (Uog 35\% and U10 22\%).

Against this backdrop, this article presents my personal reflection on the leadership styles and approaches of four senior female academics within the School of GeoSciences. I review current definitions of leadership, their styles and context within the academic setting and the implications for female academic leaders. I then present the results of interviews and discussions I held with the senior female academics about their own leadership approaches and styles, and the article concludes with a personal reflection 
of how these practices can be adopted and adapted more widely, and their impact on my own academic leadership practice.

Successful academic leadership creates an environment that inspires and facilitates the achievement of shared goals; communicates a clear direction and vision; maintains a clear and level presence and ensures team unity/cohesion where the leader is accepted and respected (Adair, 2004; Heifetz \& Laurie, 1997). A good leader will create the best environment for others to develop, but what makes someone a good leader? Defining leadership is complex, evolving and inherently subjective; not enough is known about what makes an individual an effective leader (Bryman, 2007; Bennis \& Nanus, 1997). Current research on leadership combines defining the characteristics of successful leaders and their style or approach to leadership and includes the following areas of exploration:

- $\quad$ Trait theories - identifying the individual characteristics of successful leaders.

- $\quad$ Behavioural theories - identifying the actions and behaviours of successful leaders.

- Contingency theories - noting the influence of context and situation.

- $\quad$ Power and influence theories identifying the leadership attributes that emerge as a result of positions of power and influence.

These combine to define the characteristics of successful leaders in terms of their personal attributes, interpersonal abilities and technical management skills. Personal attributes include: enthusiasm, confidence, initiative, intelligence (including emotional intelligence), warmth, humility, integrity, fairness, persistence and vision. Interpersonal abilities include: team building, outgoing personality and being compassionate. Technical management skills include analysing and evaluating problems, understanding a situation at different levels of detail, producing results, resolving conflicts, and being goal orientated with an ability to enhance the work environment (Bensimon, et al., 2000). An ideal combination of these characteristics is an important contribution to being an effective leader.

Leadership style defines the approach to providing leadership. Goleman et al. (2002) have identified six leadership styles:

- Coercive - just get on and do what I say.

- $\quad$ Authoritative - gives clear messages on what needs to be done.

- Affiliative - puts people before the task.

- Democratic - gathers ideas and support from the team.

- $\quad$ Pace-setting - sets very high personal performance standards and expects the same from the team.

- Coaching - identifies strengths and weaknesses of each team member and links them to their goals.

Tucker (1984); Bensimon et al. (1989); Bensimon \& Neumann (1993); Ramsden (1998); McCafffery (2004); Sapienza (2004); Bryman (2007); Robertson et al. (2009); and Middlehurst (2012) looked in particular at leadership in the context of higher education concluding that leadership styles need to be consultative and founded on strong teamwork and relationships. Bryman noted in his summary findings on leadership in higher education that "effective leaders create an environment or context for academics and others to fulfil their potential and interest in their work" (Bryman, 2007, p. 27) and "foster a collegial climate of mutual supportiveness and the maintenance of autonomy" (Bryman, 2007, p. 20). Sapienza notes in her Leadership Strategies in Scientific Research book that "an effective scientific leader is more likely to have an enthusiastic, energetic and passionately committed group working for them" (Sapienza. 2004, p. 3). 
Carli \& Eagly (1999) observe in their paper on the gender effects on leadership that research on gender stereotypes reveals that people consider men to have more agentic qualities (such as assertiveness and competitiveness) and women to have more communal qualities (such as being kind and supportive) (Broverman et al., 1972; Deaux \& Kite, 1993; Williams \& Best, 1990). This also extends to cognitive characteristics as well, with men perceived as more analytical and exact with women more imaginative and perceptive. This leads to an unconscious expectation that men are more likely to have an authoritative or coercive leadership style whereas women will have a more democratic or coaching leadership style which is ideally suited to the academic environment. Research by Helgesen (1990), Rosener (1990), and Glaser \& Smalley (1995) reinforces the idea that women are particularly well equipped with the key personal characteristics that contribute to natural leadership in an academic environment. However, I feel it would be naive to assume that women are naturally more suited to academic leadership and new frames of reference are required. But it is worth highlighting the study by Zenger \& Folkman (2012) for the Harvard Business Review which found that women significantly outshone men in the positive leadership competencies of taking initiative, displaying integrity, honesty and driving results, and women rated higher than men in 12 out of 16 leadership attributes.

I used the Goleman et al. (2002) definition of leadership styles as the basis of my interviews with four senior female academic staff members from the School of GeoSciences to share their reflections on their personal leadership styles and approaches. We discussed a number of topics based around: How do they describe their leadership style? What personal characteristics do they believe contribute to their effective leadership? Has their leadership evolved or changed with time? Do they adopt a different leadership style with senior colleagues than they use with junior colleagues? Had they received training in leadership? Table 1 shows a summary of their answers when asked about their styles of leadership.

None of the interviewees identified with the coercive style of leadership; two interviewees felt that coaching was not a leadership style they used very often; one interviewee expressed a wish to add coaching to her leadership style more often, as she believed it "builds teams", and one

\begin{tabular}{|c|c|c|c|c|}
\hline Leadership style & $A$ & B & C & D \\
\hline \multicolumn{5}{|l|}{ Coercive } \\
\hline Authoritative & - & $60 \%$ & $\square$ & $\square$ \\
\hline Affiliative & 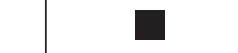 & $\square$ & $\square$ & $40 \%$ \\
\hline Democratic & $80 \%$ & $20 \%$ & $80 \%$ & $40 \%$ \\
\hline Pace-setting & $20 \%$ & $20 \%$ & $20 \%$ & $\square$ \\
\hline Coaching & $\Lambda$ & $\square$ & $\square$ & $20 \%$ \\
\hline $\begin{array}{l}\text { did not identify } \\
\text { at all with this } \\
\text { leadership style. }\end{array}$ & $\begin{array}{l}\text { occasionally } \\
\text { used this } \\
\text { leadership style. }\end{array}$ & $\begin{array}{l}\text { woul } \\
\text { this I } \\
\text { style }\end{array}$ & use & $\begin{array}{l}\text { the proportion } \\
\text { of time this } \\
\text { leadership style } \\
\text { is adopted. }\end{array}$ \\
\hline
\end{tabular}

Table 1. Results of the leadership styles interviews with four senior female academic staff members from the School of Geosciences. 
reported using coaching effectively with students. The predominance of democratic and pace-setting leadership styles with a coaching aspiration agrees with the gender stereotype of leadership. I feel this is most likely due to the fact that this style of leadership is the most successful in an academic setting and that this type of leadership is just as likely to be applied by male colleagues (future work might usefully run the same interview process with the male counterparts to see if this is the case).

All four interviewees felt that they used a mix of all the other leadership styles depending on the circumstances and individuals they were dealing with. There was a strong recognition among all interviewees that each individual they manage needs leadership styles tailored specifically to them. This is in line with the literature that indicates that the most effective leaders are those that adapt their leadership style to different circumstances and to different colleagues (Goleman et al., 2002).

Pace-setting leadership occurred in the majority of the critiques of their leadership style and from my personal observations this was something I was expecting to see with particular relevance to female leadership, as I often observe senior female academics setting themselves very high standards. All interviewees who do implement pacesetting leadership had an awareness that these high expectations needed careful monitoring so that the team is not overwhelmed by the pacesetter's demands.

The personality characteristics that led to their own leadership style that I observed in all interviewees centred on the excitement of doing innovative science, wanting to discover something new and making a difference. All interviewees felt it was important to "step up to the mark" to contribute and improve. They were all motivated by the environment of science and teaching in a multi-disciplinary international community.

A very descriptive analogy as to how the four interviewees undertake their successful leadership is the "galaxy-like spiral of change" described by Robertson \& Cox (2009), where "leadership is energy-driven not just from the core, but with energy being generated by team members themselves, self-perpetuating and to some extent self-sustaining, though still benefiting from the momentum emanating from the core leadership". The leaders I spoke with certainly enthused and inspired their teams with their own excitement and love of their science and teaching; and carried their colleagues with them in that vision and adventure. I feel that this analogy goes hand in hand with the democratic and pace-setting leadership styles preferred by the female academic leaders interviewed.

The interviewees made a number of thoughtprovoking observations (all quotations are taken from interview notes) that provided some very important insights into successful leadership practices. These are grouped into the three main themes identified at the start of this article: personal and reflective attributes, interpersonal abilities and technical management skills:

- Have an awareness of how you behave and how that influences others; "notice when you make a difference". This was particularly pertinent to the interviewees who considered themselves pacesetters as they were aware that they needed to be careful to make sure other members of the team were not given unreasonable expectations.

- Develop a thick skin; sometimes you will make decisions that are not popular with everyone.

- Be a role model, be supportive of your team, involved and interested in their research, "attend presentations your students give" to show them that they and their work are a priority for you.

- All interviewees stated empathy as a great skill and this is especially relevant to the mathematical/applied 


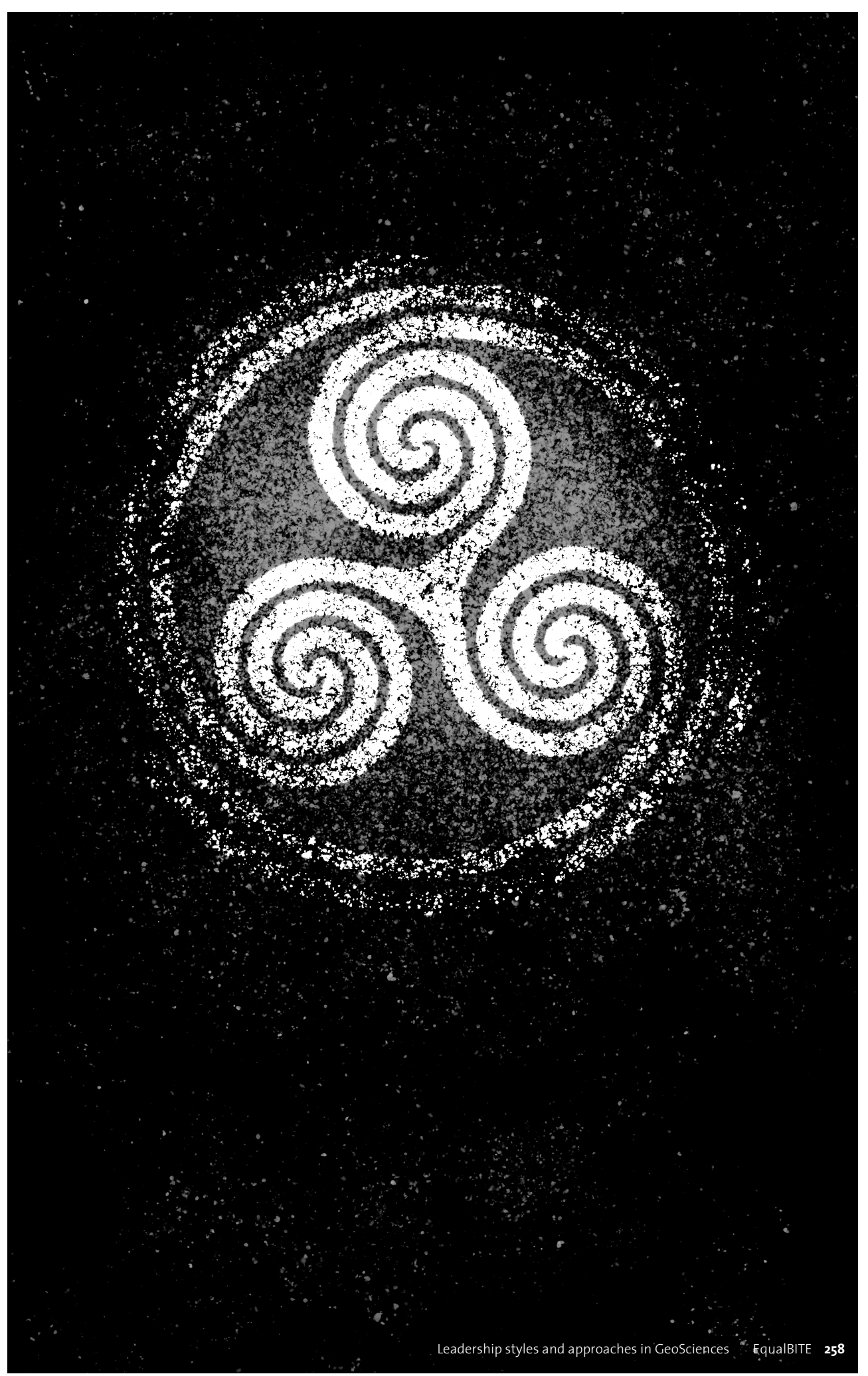


science discipline that we work within.

They saw this as giving women a

leadership edge as it helps to get

the best out of all team members.

- Being a facilitator was a recurring idea during the interviews, which is in line with the idea of a good academic leader creating an environment for academics and others to fulfil their potential. This will often involve getting the resources and management right so there is the academic freedom in which to operate.

- $\quad$ Trust the students and academic teams that you lead to operate at their best and get on with it.

- "Support from colleagues makes you feel less exposed." Talking through complex matters with a senior colleague and getting them involved is a positive step and hugely valuable. Use support network groups and be open to new connections.

- Leadership skills evolve with time, experience and confidence. With maturity you are exposed to more experiences and ideas, take on more responsibility and become more aware of what you have to deliver.

- Communication is key to good leadership, especially modes of communication. If something important or sensitive needs to be discussed, do this in person; emails are an ineffective and troublesome way of communicating, and often open to misinterpretation.

- In meetings, it is hugely important to listen properly and leave a gap in the conversation for thought. This builds trust and improves communication.

- $\quad$ Prepare for meetings or important discussions. Have a plan of the outcomes you want to achieve in any meeting and try to make sure they are achieved. Be determined to achieve the outcomes that are really important to you and don't worry about the ones that are not so important. Be really clear about your highest priorities for change and don't have too many of these.

- Be adaptable, don't be afraid to change leadership styles and even your own mindset; there is more than one way to tackle a problem.

- The democratic style of leadership was identified as particularly useful when dealing with senior male colleagues. The challenge of leading older male colleagues was raised by a few of the interviewees who were all extremely comfortable with leading students, postgraduates and peers, but felt less confident with older or dominating (and not always senior) male colleagues.

- Self-belief and confidence are very important. It was interesting to note that some of the interviewees who I regard as very confident, capable and exciting leaders often did not see that about themselves in every circumstance; personal perception is a very important part of leadership confidence. This is where the 3600 assessment (Johnson, 2004) would be a very interesting exercise and if a more in-depth analysis could be done on the results it would be fascinating to have each interviewee complete an assessment of each of the other interviewees' leadership styles and to see how their personal view of their own leadership style aligns with the external views of their leadership style.

All interviewees who had undertaken leadership training said they had benefited from it, primarily by exchanging experiences with their peers and gaining listening and problem-solving skills. It also helped in raising awareness of how their behaviour influences those around them. It was interesting to note that leadership training was offered the more senior they became, whereas on reflection some interviewees would have liked to have had this training and awareness earlier on in their careers. 
The overall leadership approach adopted by everyone interviewed was that of a hand on the tiller for gentle guidance. Providing a well-defined vision, making the goals clear, enthusing the team to achieve these goals and giving each team member the resources and space to do it themselves. One interviewee emphasised the need to "make a clear statement; don't make assumptions". This is particularly relevant to PhD students where the recommendation given was that in year one the students will require significant leadership and guidance which gradually reduces as they take ownership of their research until you become more of a guide than a leader.

In addition to the very helpful insights into what makes for successful leadership in an academic environment described above, the key messages that I personally have taken on board are: enthuse and excite - if you excite your team they will be naturally motivated and passionate about their research and develop as valued independent researchers; listen effectively and implement fair and ethical leadership, particularly in areas such as paper co-authorship and the sharing of research ideas, areas which are easily open to abuse. I would also include as important but understated leadership skills, being patient, taking a considered approach to action, and keeping a level head. This must be underpinned with selfconfidence so that I do not hang back and miss opportunities that, to quote Sheryl Sandberg (2013), I should have "leaned in" for.

And finally: to believe in yourself.

\section{Acknowledgements}

My thanks go to all the interviewees, in appreciation of their time and their insights. 